\title{
SALA DE AULA INVERTIDA: BREVES CONSIDERAÇÕES SOBRE O MÉTODO
}

\author{
FLIPPED CLASSROOM: BRIEF CONSIDERATIONS ABOUT THE METHOD
}

\author{
Marcos de Oliveira Gonçalves Toledo
}

Universidade de Uberaba, Uberaba, MG, Brasil. E-mail: toledomarcos@outlook.com.br

\section{Luiz Gustavo Rodrigues Cardoso}

Ânima Educação, Catalão, GO, Brasil. E-mail: luizgustavo77@hotmail.com

\section{François Silva Ramos}

Universidade Presidente Antônio Carlos de Uberaba, Uberaba, MG, Brasil. E-mail: francois.ramos@ hotmail.com

DOI: https://doi.org/10.46550/amormundi.v2i8.140

Recebido em: 10.12.2021

Aceito em: 04.01.2022

Resumo: A presente pesquisa foi elaborada com o objetivo de expressar sobre a sala de aula invertida, sendo um método que ainda não possui expressão dentro do Brasil, mas que tem ganhado grande proporção em outros países. Para tal, foram abordados aspectos a respeito da sala de aula invertida como a sua história, seu conceito, seus benefícios e o papel do professor. Através da análise de artigos e livros, se realizou pesquisa bibliográfica e hipertextual, que nos permitiu concluir que o método de sala de aula invertida tem muito a oferecer, estando além da simples utilização de meios tecnológicos. Logo, para que alcance sua efetividade, é necessário que a sala de aula sofra grandes transformaçōes.

Palavras-chave: Method; Flipped classroom; Teacher.

Abstract: The present research was elaborated with the objective of expressing about the inverted classroom, being a method that still does not have expression within Brazil, but that has gained great proportion in other countries. To this end, aspects about the inverted classroom were addressed, such as its history, its concept, its benefits and the role of the teacher. Through the analysis of articles and books, bibliographic and hypertextual research was carried out, which allowed us to conclude that the inverted classroom method has a lot to offer, going beyond the simple use of technological means. Therefore, in order to achieve its effectiveness, it is necessary that the classroom undergoes major transformations.

Keywords: Method; flipped classroom; Teacher. 


\section{Introduçáo}

presente pesquisa tem por objetivo expressar à respeito do método de sala de aula

Linvertida, por meio de abordagem da sua idealização, seguindo para o seu conceito, posteriormente, abordando sua rotina simultaneamente aos seus desafios e então adentrando nos aspectos de seus benefícios.

Dentro das expressóes que a envolvem, será também demonstrado sobre o que é a sala de aula invertida e como a mesma ocorre, momento em que serão esclarecidos pontos importantes como: qual o real papel dos professores e como este deve ser desenvolvido, como as atividades devem ser executadas, quais as atividades acontecem dentro e quais as atividade acontecem fora da sala de aula, entre outras abordagens de igual relevância.

Por se tratar de um tema recente e com abordagens diversas e conceitos ainda não definidos, não está dentro dos objetivos esgotar o assunto ou conceitualizar e definir a sala de aula invertida, mas sim contribuir com os estudos da área e auxiliar na produção de estudos e materiais por pesquisadores da área.

Para a elaboração deste trabalho fora realizada pesquisa bibliográfica e hipertextual, sendo que parte dos artigos e trabalhos utilizados foram traduzidos do inglês, onde houveram dificuldades de encontrar fontes do Brasil, visto que o país ainda não expandiu exponencialmente o método em questão.

Durante a realização desta presente pesquisa, foi possível aos autores tomar por conclusão que a sala de aula invertida tem muito a contribuir com a educaçáo, principalmente no tocante à otimização do tenso e a possibilidade de tornar o acadêmico mais autodidata.

\section{Sala de aula invertida: aspectos históricos}

A aula invertida, idealizada pelo educador americano Salman Khan, foi desenvolvida com o objetivo de resolver os problemas que acadêmicos do ensino médio possuíam com relação às atividades presenciais, que eram a ausência dos acadêmicos nas mesmas e, consequentemente, a perca dos conteúdos lecionais pelos seus professores.

Após a idealização deste projeto e da grande repercussão que ele teve - principalmente nas redes sociais com grandes números de visualizaçóes de vídeos explicativos - a sala de aula invertida despertou grande interesse em diversos educadores de diferentes áreas, mas em especial, de dois educadores também americanos que aprofundaram seus estudos em tal.

Destarte, em 2007 o modelo idealizado por Khan começou a ser desenvolvido por estes educadores que são Jonathan Bergmann e Aron Sam, os quais receberam o Prêmio Presidencial por Excelência no Ensino de Matemática e Ciências (Presidential Award for Excellence for Math and Science Teaching) nos Estados Unidos da América em 2002 e 2009, respectivamente.

Um dos pontos a chamar atenção de Bergmann e Sam estavam no modelo da aula invertida, onde de acordo com Datig e Ruswick (2013),

(...) as instruçóes dos conteúdos se realizam fora da sala de aula por meio de vídeos-aula, leituras e outras mídias, sendo o tempo de sala de aula liberado para realização de atividades ativas, nas quais os alunos praticam e desenvolvem o que aprenderam com o auxílio e supervisão do professor. 
Porém, se engana aqueles que pensam que a sala de aula invertida exclui a participação do professor e coloca o aluno como ponto principal de geração de conteúdo, pois não há um modelo onde a classe é de fato invertida - com exceçôes de atividades acadêmicas como apresentação de trabalhos e similares -, sendo indicado então apenas a adaptação da sala de aula conforme a realidade dos acadêmicos.

\section{Conceito}

$\mathrm{Na}$ abordagem do assunto sobre a sala de aula invertida, se tratando de uma temática recente, é comum encontrarmos diversos conceitos que buscam o definir, mas não podendo ser definido ainda como uma ciência exata e como possuindo um conceito específico.

Portanto, apesar desta dificuldade de conceitualizaçáo, destacam-se expressóes que buscam o definir, como no caso de Bishop e Verleger (2013) que definem a Sala de Aula Invertida como sendo

(...) uma técnica educacional que consiste em duas partes: atividades de aprendizagem interativas em grupo em sala de aula e orientação individual baseada em computador fora da sala de aula.

Com relação à divisão em duas partes das atividades a serem realizadas, sendo parte fora e parte dentro da sala de aula, Pavanelo e Lima (2017), explicam que esta é desenvolvida no seguinte formato

A Sala de Aula Invertida é constituída, basicamente, por duas componentes: uma que requer interação humana (atividades em sala de aula), ou seja, a ação; e outra que é desenvolvida por meio do uso das tecnologias digitais, como vídeoaulas (atividades fora da sala de aula).

O fato de as atividades serem realizadas tendo o aluno como ponto central das teorias de aprendizagem tem grande relevância dentro deste contexto, sendo que através dele o aluno terá base filosófica para o desenvolvimento de suas atividades. Ou seja, a SAI irá proporcionar a otimização do tempo para que, em sala de aula, todo o tempo não seja destinado á aulas expositivas.

Neste contexto é que complementa Valente (2014), ao citar que

a sala de aula invertida é uma modalidade de e-learning na qual o conteúdo e as instruçóes são estudados on-line antes de o aluno frequentar a sala de aula, que agora passa a ser o local para trabalhar os conteúdos já estudados, realizando atividades práticas como resolução de problemas e projetos, discussão em grupo, laboratórios etc.

Ainda dentro desse contexto, Andrade et al (2019) expressam que,

$\mathrm{Na}$ sala de aula invertida, a ideia é não trabalhar a transmissão de conteúdo em sala, mas a aplicação dos assuntos vistos em casa, de maneira prática, dinâmica e ativa por parte do aluno.

Ou, de forma mais simplista, é possível dizer que, tratando de SAI, "o que tradicionalmente é feito em sala de aula, agora é executado em casa, e o que tradicionalmente é feito como trabalho de casa, agora é realizado em sala de aula” (BERGMANN, SAMS, 2012). E para compreender mais sobre o modelo, alguns educadores realizaram estudos almejando identificar quais os resultados que a SAI demonstrava, sendo a partir das pesquisas puderam definir que 
algumas delas indicaram um melhor desempenho de seus alunos em avaliaçóes, outras relataram um indicativo de que classe se mostrou mais envolvida com o desenvolvimento do conteúdo e que os alunos sentiam maior confiança em sua capacidade de aprender de forma independente (MORAN e MILSOM, 2014).

Porém, no Brasil, a SAI é algo muito novo e que até então não tem sido difundido dentro do contexto educacional, sendo que até mesmo as pesquisas que envolvem o tema não têm ganhado demasiada proporção.

\section{Rotina e desafios}

Para se desenvolver de forma efetiva a SAI, é imprescindível que seja estabelecida uma rotina, na qual demonstrará e indicará passos a serem dados, com o objetivo de esclarecer questôes e prosseguir com o conteúdo de forma clara, superando todos os desafios que o método proporciona.

E, ao serem indagados sobre a rotina, os desenvolvedores da SAI, Bergmann e Sams, expressam a respeito que

Em essência, começamos cada aula com alguns minutos de discussão sobre o vídeo que foi visto em casa. Um dos inconvenientes do modelo invertido é o de que os alunos não podem fazer de imediato as perguntas que lhes vêm à mente, como teria sido o caso numa aula ao vivo (BERGMANN; SAMS, 2012).

O sentido de se discutir a respeito do vídeo que foi assistido em casa pelos acadêmicos está no fato de que as dúvidas que não puderam ser tiradas no momento do vídeo sejam esclarecidas antes de que os conteúdos sejam avançados. Porém, uma forma que os autores utilizam para tal é ensinarem os seus acadêmicos à assistirem aos vídeos de forma clara eficaz, sendo que para isso há o incentivo para "desligar iPods, telefones e outras distraçôes enquanto assistem ao vídeo" (BERGMANN; SAMS, 2012).

Porém, o fato de estar atento a todos os detalhes nem sempre vai proporcionar o devido esclarecimento que o acadêmico precisar, sendo então que outros passos são tomados, como no caso de orientar os alunos a

(...) adotarem o método Cornell de anotaçóes, em que transcrevem os pontos importantes, registram quaisquer dúvidas que lhes ocorram e resumem o conteúdo aprendido. Os alunos que praticam esse modelo de anotaçáo geralmente levam para a sala de aula questóes pertinentes que nos ajudam a abordar controvérsias e equívocos comuns (BERGMANN; SAMS, 2012).

As perguntas servem até mesmo de ponto de partida para as discussôes que são realizadas dentro da sala de aula, sendo um gatilho para o início das atividades, que irá também proporcionar para os professores a possibilidade de compreender se os vídeos foram esclarecedores e quais os pontos

A partir desse momento, os autores relatam que entram em um segundo momento, sendo este o momento em que

Passamos aos alunos as tarefas do dia a serem executadas na sala de aula. Pode ser experiência em laboratório, atividade de pesquisa, solução de problemas ou teste. (...) os alunos, em geral, realizam mais de uma dessas atividades em qualquer uma das sessōes (BERGMANN; SAMS, 2012). 
Nesse aspecto pode se identificar certa semelhança com o modelo tradicional, pelo fato de que a avaliação dos trabalhos, das experiências realizadas no laboratório como também da correçấo das provas não muito se diferenciam. Porém, o que deve mudar radicalmente é o papel do professor, pois, dentro do SAI, os professores deixam de lado seus papéis como meros transmissores de informaçóes, mas passam a assumir a função como orientador e/ou como tutor dos acadêmicos.

\section{A aplicação e os benefícios}

Assim como o papel do professor exige uma transformação, é necessário que a sala de aula também sofra uma alteração estruturação para a aplicação do método de sala de aula invertida, mas não no sentido de direção do professor e dos acadêmicos, ou que o professor deva estar ouvindo os acadêmicos falarem na frente da sala, entre outras, mas se trata da forma em que a aula será desenvolvida.

A sala de aula invertida, como visto antes, permite uma maior interação entre os próprios acadêmicos, que previamente ao momento presencial na sala de aula já viram vídeos e explicaçóes à respeito do conteúdo, para que então venham a debater sobre dentro da sala.

Logo, para facilitar esse contato e o desenvolvimento da aula presencial, Andrade et al (2019) orienta que "a disposição das carteiras pode ser alterada, promovendo, ainda que de forma tímida, o desenvolvimento de uma nova cultura da sala de aula, diferente da que estamos acostumados".

Esta modificação está estritamente ligada à ideia contrária que causa o modelo tradicional de fileiras e posiçôes da sala de aula, no qual

Alunos enfileirados, olhando todos numa única direção, pressupóe que alguém estará detendo o conhecimento, situação que nos remete a figura docente como alguém que mais que é a fonte da sabedoria, e os ouvintes são os receptáculos (ANDRADE et al, 2019).

A ideia da sala de aula invertida é exatamente oposta a consideração do acadêmico como um receptáculo, mas trata o professor como mediador e o acadêmico como, de certa forma, autônomo.

E este é um dos pontos elencados como benéficos por Oliveira, Araújo e Veit (2016) da sala de aula invertida, sendo que os mesmos elegem 08 (oito) pontos positivos, que são

a) Ressignifica o papel do professor; b) Não implica necessariamente no uso de videoaulas; c) Coloca o aluno no centro do processo educativo; d) Podem auxiliar no desenvolvimento de hábitos de estudos nos estudantes; e) Pode estimular o desenvolvimento de habilidades relacionadas ao trabalho colaborativo; f) Leva em consideraçáo os conhecimentos prévios dos alunos; g) Auxilia os alunos no desenvolvimento da capacidade de reflexão e da habilidade de elaborar boas perguntas; h) Lida com a heterogenia na sala de aula.

Logo, é possível notarmos que, a sua aplicação eficaz está condicionada a uma série de fatores, onde todos os pontos acima citados devem ser bem trabalhados e desenvolvidos para que a sala de aula invertida chegue aos seus objetivos almejados. 


\section{Conclusáo}

Por mais que trate de um método muito novo, desenvolvido há cerca de 15 (quinze) anos, através dos resultados de pesquisas realizadas, é possível compreender que a sala de aula invertida tem contribuído muito para o desenvolvimento dos acadêmicos que estão inseridos nela.

Porém, é possível compreender também que não se trata apenas da utilização de ferramentas tecnológicas, mas se trata de grandes alteraçóes que devem ocorrer, partindo das modificaçóes do papel do professor dentro e fora da sala de aula, passando pelas análises de conteúdo e de aprendizagem que buscam a melhoria contínua dos processos e indo até os acadêmicos, que precisam aprender e compreender o método para que o mesmo tenha efetividade.

Ainda que no Brasil o método não seja tão utilizado e não tenha ganhado muito espaço, á instituiçôes que buscam trabalhar nesse formato, principalmente no ensino superior, visando a autonomia do acadêmico como também o seu desenvolvimento com relação aos estudos.

$\mathrm{E}$, ainda que não tenham muitos materiais para sejam utilizados como fonte de pesquisa sobre o tema, há a possibilidade de compreender, principalmente pelos materiais dos desenvolvedores do método, e também aplica-los dentro das salas de aula.

\section{Referências}

ANDRADE, Luiz Gustavo da Silva Bispo. JESUS, Lucas Antonio Feitosa. FERRETE, Rodrigo Bozi. SANTOS, Ronney Marcos. A sala de aula invertida como alternativa inovadora para a educação básica. Revista Eletrônica Sala de Aula em Foco, Volume 8, Número 2, 4-22, 2019.

BERGMANN, Jonathan. SAMS, Aaron. Sala de aula invertida: Uma metodologia ativa de aprendizagem. Livros Técnicos e Científicos Editora: Rio de Janeiro, 2012.

BISHOP, J. L.; VERLEGER, M. A. The Flipped Classroom: A Survey of the Research. In: ASEE ANNUAL CONFERENCE \& EXPOSITION, 120., 2013, Atlanta. Anais... local: Washington DC, American Society for Engineering Education, 2013. p. 1-18. Disponível em: <http://www.studiesuccesho.nl/wp-content/uploads/2014/04/flipped-classroom-artikel. pdf $>$.

DATIG, I.; RUSWICK, C. Four Quick Flips: Activities for the Information Literacy Classroom. College \& Research Libraries News, v. 74, n. 5, p. 249-251, 257, 2013.

Disponível em: <http://crln.acrl.org/content/74/5/249.full\#sec->

MORAN, K.; MILSOM, A. The Flipped Classroom in Counselor Education. Counselor Education and Supervision, 2015. Disponível em: <http://onlinelibrary.wiley.com/ doi/10.1002/ceas.2015.54.issue-1/issuetoc>.

OLIVEIRA, T. E., ARAUJO, I. S., VEIT, E. A. Sala de Aula Invertida (Flipped Classroom): inovando as aulas de física. Física na Escola, v. 14, n. 2, 2016. Disponível em: <http://www1. fisica.org.br/fne/phocadownload/Vol14-Num2/a02.pdf>.

PAVANELO, Elisangela. LIMA, Renan. Sala de Aula Invertida: a análise de uma experiência na disciplina de Cálculo I. Bolema, v. 31, n. 58, p. 739-759, 2017. Disponível em: < https:// 
www.scielo.br/j/bolema/a/czkXrB369jBLfrHYGLV4sbb/?lang=pt\&format=pdf>.

VALENTE, J. A. Aprendizagem Ativa no Ensino Superior: a proposta da sala de aula invertida. Notícias, Brusque, 2013. Disponível em: <https:/www.unifebe.edu.br/site/docs/ arquivos/noticias/2014/valente.pdf>. 